\title{
Macro-Level Studies of Direct and Indirect Relationships between SDG 4 and the 16 SDGS
}

\author{
Anthony Wakwe Lawrence ${ }^{1 *}$, Noel Ihebuzor ${ }^{2}$, Damiete Onyema Lawrence ${ }^{3}$ \\ ${ }^{1}$ Community Inter-Relations and Conciliation Initiative-CIRCI (Non-Governmental Organization), Port Harcourt, Nigeria \\ ${ }^{2}$ Independent Education and Development Consultant, Abuja, Nigeria \\ ${ }^{3}$ Rivers State University, Port Harcourt, Nigeria \\ Email: *tonylawrence942@gmail.com
}

How to cite this paper: Lawrence, A. W., Ihebuzor, N., \& Lawrence, D. O. (2020). Macro-Level Studies of Direct and Indirect Relationships between SDG 4 and the 16 SDGS. Modern Economy, 11, 1176-1194. https://doi.org/10.4236/me.2020.116085

Received: May 10, 2020

Accepted: June 21, 2020

Published: June 24, 2020

Copyright $\odot 2020$ by author(s) and Scientific Research Publishing Inc. This work is licensed under the Creative Commons Attribution International License (CC BY 4.0).

http://creativecommons.org/licenses/by/4.0/ (c) (i) Open Access

\begin{abstract}
SDG 4 is a foundational goal having an enabler role for the realisation of most of the other SD goals. Seven SDGs $(3,8,12,13,14,16$ and 17) have targets that are directly related to SDG 4 which are education and or capacity building in nature. The remaining 9 other SDGs were assessed to be indirectly related with SDG 4. This paper examined SDG 4 from 2 levels: Goal to Targets (SDG 4 versus the targets/goals of the other 16 SDGs) and Targets to Targets, which is a comparison between the 10 SDG 4 targets and the remaining 159 targets of the others. We identified 38 direct-relationships and 322 indirect relationships between SDG 4 targets and the targets of the remaining 16 SDGs. These findings confirm that Sustainable Development Goals are inter-dependent (direct relationships) or interrelated (indirect relationships) in many respects. At the level of interventions, the school feeding programme which can qualify as an intervention to reduce the incidence of out of school children amply illustrates inter-relationships, as it is shown to be impacting directly on SDG 2 by addressing hunger and SDG 1 (poverty) through increased revenues for farmers and service providers. For developing nations to derive the greatest benefits from the implementation of the SDGs, they must give priority to interventions that have the potentials to achieve multi-goal needs/inherent positive multiplier effects.
\end{abstract}

\section{Keywords}

SDG-Mapping, Inter-Linked, Inter-Dependent/Directly-Related, Inter-Related/Indirectly-Related

\section{Introduction}

The Sustainable Development Goals (SDGs) were launched in 2015. The 17 objectives were considered as worthy successors of the 8 Millennium Development 
Goals (MDGs) which they replaced and expressed the aspirations of the whole world that global development was indeed possible if the 17 goals were pursued in earnest and met. They were launched in 2015 amidst great euphoria and belief in the global partnership for human development. One noticeable feature of the SDGs which distinguished them from the MDGs was the fact that a number of its goals were phrased as single focus goals in contradistinction to the MDGs where some of them had been phrased as joint focus or fused focus goals. Thus, in the MDGs, the pursuit of the elimination of poverty and hunger was fused as one goal, wherein the SDGs are now phrased as two distinct goals-No poverty as goal 1 and elimination of Hunger as goal 2. A similar inclination to single focusing in the phrasing of goals is also noticeable in the presentation of goals that dealt with environmental sustainability which were now split into several distinct goals in the SDGs, some touching on climate change, another touching on water and sanitation, two others touching on life above and below water, and yet another touching sustainable consumption and production whilst one focused on cities. These developments in the areas of sharper and single focus phrasing were driven by concerns to reap the benefits of better accountability and improved monitoring and evaluation which would normally accompany such sharper focusing. They were also, no doubt, recognition of the increasing development prominence and stature that were now being accorded to these areas. Given the increase in the number of SDGs, one is right in wondering about the degree of relationship between these numerous goals. What is the degree of coherence between these many goals, for example? Was the increase in numbers achieved through the sacrifice of relationships and coherence? Questions like these were the ones that agitated the minds of the researchers as they conceived of this study on the importance of SDG 4 and its direct and indirect relationship with the other 16 SDGs.

Another impetus for this study was the wish to investigate to what extent the SDGs lived up to descriptions that they are indivisible and integrated into their phrasing and actual effect. If indeed they are, then an analysis of their contents and targets would bring out close inter-connectedness, overlaps and mutual reinforcements.

The study will show the interconnectedness, integration and mutual reinforcement qualities the goals have with SDG 4. Education and lifelong are now recognised universally as the foundational pillars on which all other aspects of human development are built. Education, whatever form it takes, be it formal, informal or non-formal is that systematic socialisation that arms peoples and societies with skills, capacities, competencies, cognitions, and attitudes necessary for sustainable transformations, growth and development. It is not an accident that societies with the highest levels of education are also those with the best performances on indicators of human development. But beyond arming peoples and societies with skills, Education also confers certain positive externalities on societies. Such externalities include improvements in social cohesion, the building of social capital, reductions in child mortality and maternal mortality, improve- 
ment in functional literacy, increases health-seeking behaviour, greater receptivity to ideas, demographic transition and decline in fertility rates (Ihebuzor, 2014). Indeed it is now generally accepted that education breaks the inter-generational transmission of poverty and thus positions societies for further sustainable and inclusive development, a development that leaves no one behind and which builds equity, reduces exclusion and enables optimal participation by all in society. All the foregoing, it will be recognised, are principles that inspired the SDGs and which animate their implementation. If Education confers all these benefits, an examination of SDG 4 and its targets should reveal their multiple links and enabling interconnectedness with a sizeable number of other SDGs.

We shall look at SDG 4 from two main perspectives: Relationships between SDG 4 as a goal with the other 16 SDGs (goals/targets) and the relationships between the 10 targets of SDG 4 with the 159 targets of the other 16 SDGs.

For ease of processing and recall, the 17 SDGs are presented in Table 1 below and the next 2 figures present the SDG 4 targets.

The SDG 4 and targets (Figure 1, Table 2).

Table 1. Showing the titles of the sustainable development goals.

\begin{tabular}{|c|c|}
\hline SDG & Sustainable development goals description \\
\hline 1 & End poverty in all its forms everywhere \\
\hline 2 & $\begin{array}{l}\text { End hunger, achieve food security and improved nutrition and promote } \\
\text { sustainable agriculture }\end{array}$ \\
\hline 3 & Ensure healthy lives and promote well-being for all at all ages \\
\hline 4 & $\begin{array}{l}\text { Ensure inclusive and equitable quality education and promote lifelong } \\
\text { learning opportunities for all }\end{array}$ \\
\hline 5 & Achieve gender equality and empower all women and girls \\
\hline 6 & Ensure availability and sustainable management of water and sanitation for all \\
\hline 7 & Ensure access to affordable, reliable, sustainable and modern energy for all \\
\hline 8 & $\begin{array}{l}\text { Promote sustained, inclusive and sustainable economic growth, full and } \\
\text { productive employment and decent work for all }\end{array}$ \\
\hline 9 & $\begin{array}{l}\text { Build resilient infrastructure, promote inclusive and sustainable industrialization } \\
\text { and foster innovation }\end{array}$ \\
\hline 10 & Reduce inequality within and among countries \\
\hline 11 & Make cities and human settlements inclusive, safe, resilient and sustainable \\
\hline 12 & Ensure sustainable consumption and production patterns \\
\hline 13 & Take urgent action to combat climate change and its impacts \\
\hline 14 & $\begin{array}{l}\text { Conserve and sustainably use the oceans, seas and marine resources for } \\
\text { sustainable development }\end{array}$ \\
\hline 15 & $\begin{array}{l}\text { Protect, restore and promote sustainable use of terrestrial ecosystems, sustainably } \\
\text { manage forests, combat desertification, and halt and reverse land degradation } \\
\text { and halt biodiversity loss }\end{array}$ \\
\hline 16 & $\begin{array}{l}\text { Promote peaceful and inclusive societies for sustainable development, provide access } \\
\text { to justice for all and build effective, accountable and inclusive institutions at all levels }\end{array}$ \\
\hline 17 & $\begin{array}{l}\text { Strengthen the means of implementation and revitalize the global partnership } \\
\text { for sustainable development }\end{array}$ \\
\hline
\end{tabular}

Source: (United Nations, 2015a). 


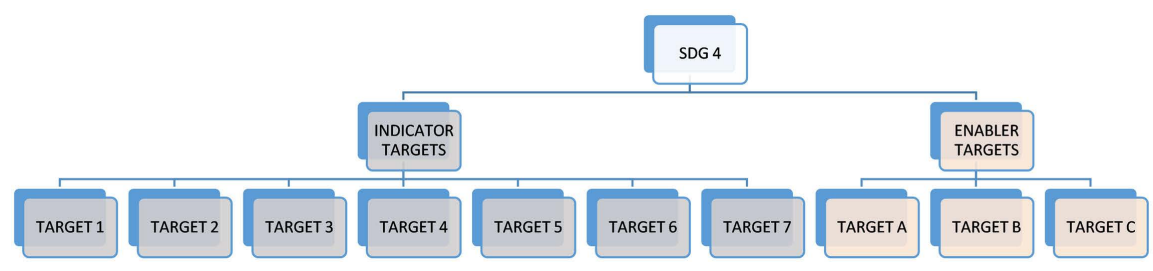

Figure 1. A diagrammatic elucidation of the 7 SDG 4 targets and the 3 enabling targets. (Source: Conceptualized by the Researchers).

Table 2. Showing the descriptions of the SDG 4 targets.

SDG 4 TARGETS DESCRITION

TARGET 1

By 2030, ensure that all girls and boys complete free, equitable and quality primary and secondary education leading to relevant and Goal-4 effective learning outcomes

By 2030, ensure that all girls and boys have access to quality early

TARGET 2 childhood development, care and pre-primary education so that they are ready for primary education

By 2030, ensure equal access for all women and men to affordable

TARGET 3 and quality technical, vocational and tertiary education, including university

By 2030, substantially increase the number of youth and adults who

TARGET 4 have relevant skills, including technical and vocational skills, for employment, decent jobs and entrepreneurship

By 2030, eliminate gender disparities in education and ensure equal access to all levels of education and vocational training for the vulnerable, including persons with disabilities, indigenous peoples and children in vulnerable situations

TARGET 6

By 2030, ensure that all youth and a substantial proportion of adults, both men and women, achieve literacy and numeracy

By 2030, ensure that all learners acquire the knowledge and skills needed to promote sustainable development, including, among others, through education for sustainable development and sustainable lifestyles, human

TARGET 7 rights, gender equality, promotion of a culture of peace and non-violence, global citizenship and appreciation of cultural diversity and of culture's contribution to sustainable development

Build and upgrade education facilities that are child, disability and TARGET A gender sensitive and provide safe, nonviolent, inclusive and effective learning environments for all

By 2020, substantially expand globally the number of scholarships available to developing countries, in particular least developed countries,

TARGET B small island developing States and African countries, for enrolment in higher education, including vocational training and information and communications technology, technical, engineering and scientific programmes, in developed countries and other developing countries

By 2030, substantially increase the supply of qualified teachers,

TARGET C including through international cooperation for teacher training in developing countries, especially least developed countries and small island developing states

Source: (United Nations, 2015b). 


\section{Literature Review}

The SDGs, both in their phrasing and aspirations present the world a good example of planning development which reflects the importance of recognizing and maintaining connections between the various elements of development. Such quality in the SDGs is commendable since several authors have shown that SD challenges which SDGs themselves address are also interrelated and inter-dependent (Griggs et al., 2014; Lawrence, 2018).

Griggs et al. (2014) have argued that the SDGs are set in a way that each goal though addressing a specific set or groups of challenges are equally interrelated in addressing other challenges. Such inter-relationships in a way also reflect the interrelationships that are involved in the concept of development itself. Such inter-relationships also underscore the centrality of systems thinking to any proper treatment of the issue of development in general and the SDGs in particular. Systems thinking with its emphasis on a holistic and integrated multistakeholder approach and its recognition of the role of inter-relatedness and connectedness are thus central to examinations of the SDGs in their intentions and effects (Reynolds et al. 2018; UN ESCAP, 2019). Systems thinking stresses synergy, organic interactions, moving parts, mutual influences, and interdependencies. Senge (1990) defines it thus "Systems thinking is a framework for seeing interrelationships rather than things, for seeing patterns rather than static snapshots. It is a set of general principles spanning fields as diverse as physical and social sciences, engineering, and management." INCOSE UK (2010) on the other hand opined that "Systems thinking is a way of thinking used to address complex and uncertain real-world problems. It recognises that the world is a set of highly interconnected technical and social entities that are hierarchically organised producing emergent behaviour." (Freeman \& Yearworth, 2014).

Scholars who have examined the SDGs have arrived at findings that are suggestive of the influence of system thinking in their formulation. Such scholars have also shown intricately and graphically the interrelatedness of the SDGs (GSDR -ICSU Report (2015); Nilsson et al. (2016). Their findings are that the SDGs are formulated in a way that many of them are directly or indirectly interrelated.

Working within such a systems paradigm, the interdependence of some SDGs can be illustrated by examining the impact of the school feeding programme on the attainment of SDG 4. In some countries and some contexts, transformative pedagogy and school feeding are technics used as strategies to pull pupils to school and to ensure their retention whilst at the same time ensuring that learning is taking place in many respects and interrelated during the pedagogy session, it is important to integrate cognitive and affective factors to enhance students interest and engagement in learning (Littledyke, 2008). It is also important towards providing food for needy and hungry students during school. This means that while trying to address an issue of access and retention in school, policymakers adopting the approach of school feeding are also helping to resolve 
another development challenge, in this particular case, that of food security and nutritional adequacy for the growing child. For example, the Nigerian government set out to reduce out of school children by introducing a school feeding programme for children at the basic education level. This had the effect of attracting and retaining the children of the poor to school, thereby raising net enrolment rates. But it was also producing another effect which was that of ensuring that these children had at least one balanced meal in the day, thus addressing the concerns of SDG 2. But such school feeding programmes also amount to some form of social transfer programme which addresses issues of Poverty; thus SDG 1 is also addressed. The purchase of foodstuff from farmers would result in a boost to the agricultural sector in terms of incentivizing greater farm outputs and other services provided in the process, like food preparation, transportation, storage etc., will generate a virtuous cycle of links and interactions within the society and its systems and subsystems in perpetuity, thanks to the exploitation of interconnectedness in society, an interconnection which the systems thinking underpinning much of the SDGs productively exploits. It is also worth suggesting that during actual teaching-learning sessions, it is important to integrate cognitive and affective factors to enhance students' interest and engagement in learning (Littledyke, 2008), as well as providing food for the students during school.

An interesting observation is a recognition that whereas most relationships are positive, some could turn out to be negative if due attention is not paid to interactions at the implementation level. For instance, Nilsson et al. (2016) gave some examples of how interactions can be negative. They stated that increased food production can result in more use of pesticides or fertilizers which in turn can negatively affect the environment. So too will be increased use of fossil fuel to meet national energy needs as pollution could increase with a potential negative impact on the environment. Thus, though in such situations, one SDG will be improved upon, another SDG may suffer because of the negative impact. This finding invites scholars of the SDGs to the possibility of unintended outcomes. Such sensitivity to and anticipation of the possibility of unintended negative interactions leading to suboptimal outputs and outcomes is thus vital at the implementation level if planned outcomes are to be achieved at the right level of optimality. Activities and actions at the implementation, monitoring and evaluation levels must, therefore, be on the lookout for such unintended outcomes. The 2030 Agenda has stated the need for inter-linkages and interactions among the SDGs, and the importance of looking at the SDGs holistically as an "indivisible whole". At the same time, sustainable development practitioners know that situations could arise that make trade-offs necessary.

With regard to empirical work in this area, Zhou, Moinuddin, \& Xu (2017) undertook a social network analysis of the 169 targets in the 17 SDGs. Using a classification principle where 0 was used to mark no relationship and 1 to indicate a relationship, they conducted a pairwise ranking of each of these 169 tar- 
gets. Their findings revealed a complex interrelationship among these targets with stronger relationships among those targets with similar foci.

Nilsson et al. (2016) in the paper "Mapping interactions between the sustainable development goals: lesson learned and ways forward" gave the following seven types of interactions between SDG targets (Table 3).

Table 3. Showing the seven types of interactions between SDG targets.

\begin{tabular}{cl}
\hline Interaction Label & \multicolumn{1}{c}{ Meaning } \\
\hline+3 & Progress on one target automatically delivers progress on another \\
+2 & Progress on one target makes it easier to make progress on another \\
+1 & Progress on one target creates conditions that enable progress on another \\
0 & There is no significant link between two targets' progress \\
-1 & Progress on one target constrains the options for how to deliver on another \\
-2 & Progress on one target makes it more difficult to make progress on another \\
-3 & Progress on one target automatically leads to a negative impact on another \\
\hline
\end{tabular}

Source: Nilsson et al. (2016).

This paper synthesizes experiences and insights from the application of a new conceptual framework for mapping and assessing SDG interactions using a defined typology and characterization approach.

ICSU (2017) reported a total number of 316 interactions connected to SDG 2, 3,7 and 14, and showed that around $80 \%$ of the interactions examined were positive, while about $20 \%$ were negative.

Lawrence \& Lawrence (2019) had tried to show how the targets of SDG 1 is directly inter-related with the other SDGs: SDG 1.1 to SDG 8; SDG 1.2 to SDG 5 and SDG 10; SDG 1.3 to SDG 10; SDG 1.4 to SDG 8, SDG 9, SDG 10, SDG 11 and SDG 16; SDG 1.5 to SDG 11 and SDG 13; SDG 1.6 to SDG 17; SDG 1.7 to SDG 5, SDG 9, SDG 10, SDG 16 and SDG 17. Lawrence \& Lawrence (2019) equally used a pairwise comparison to show some direct and indirect Inter-Relationships amongst the SDGs. They stated that 99\% of inter-dependency between goals existed. From the examples given above using SDG 1 and the pairwise comparison methodology applied, the researchers were able to demonstrate clearly that the SDGs are interrelated and inter-dependent. Based on their findings, Lawrence \& Lawrence (2019) then divided the 17 goals into 5 groups and listed SDG 4 (Quality education), SDGs 9 (Innovation and infrastructure), 11 (Sustainable cities), 12 (Sustainable consumption and production) and 17 (Partnership to achieve the goal) as those that were most capable of encouraging transformative capacities and continuous improvement of their goals and showed these goals have the same effect on all the other goals. It is worthy to note that SDG 4 is in this group.

The rest of the paper now explores SDG 4 concerning its links with the other SDGs. The section commences by recalling SDG 4 which reads-"Inclusive and equitable quality education and promote life-long learning opportunities for alp". This is then followed by a description of the method of analysis that was adopted 
for the current study, the application of the method to examining relationships between SDG 4 and the other 16 SDGs and the presentation and discussion of the findings.

Method of study-the researchers systematically went through all the 16 SDGs and SDG 4, including all their 169 targets. Each target was examined to see in what way its phrasing could be suggestive of activities, outputs and targets associated with education and or lifelong learning. Such activities include those we normally would associate with IEC, Behaviour Change Communication and Communication for Behaviour change. SDGs and their targets were divided into those with direct links with SDG 4 and these were those with words like "educate, provide information, and expose community members to training" etc. Included in this group would, therefore, be those SDGs whose targets call for actions that involve activities related to education, information dissemination, and public awareness, behaviour change communication all of which could be conveniently classified as education-whether this education is formal, informal or non-formal.

On the other hand, a target such as "double agricultural production through... and knowledge" or "empower youths" is seen as an indirect relationship. In some other cases, some targets are stated in ways we described as enabling, an example being the use of ICT to increase and extend the reach of extension services. Such SDGs are then described as having implications and applications for SDG 4.

What follows below are the findings obtained when we applied this classification grid to the SDGs.

\section{The Relationships between SDG 4 and the Other 16 SDGS}

\subsection{Assessing SDG 4 (as a Goal) to the Other 16 SD Goals/Targets}

Figure 2 showing in a cyclical format SDGs with several targets that are directly related to SDG 4. The 9 SDGs coloured yellow have no direct relationships with SDG 4 but have a number of indirect relationship links.

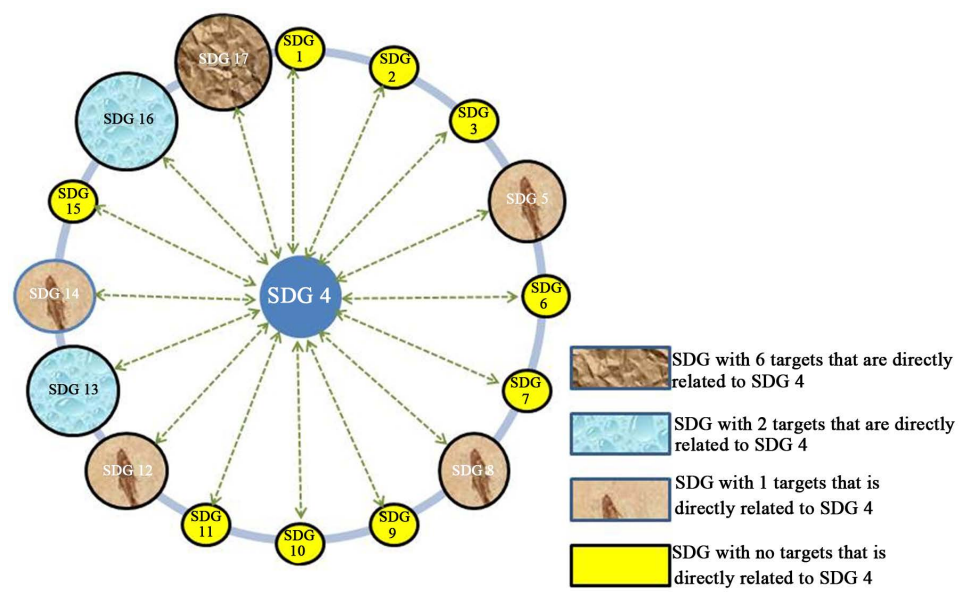

Figure 2. Source: Conceptualized by the researchers. 


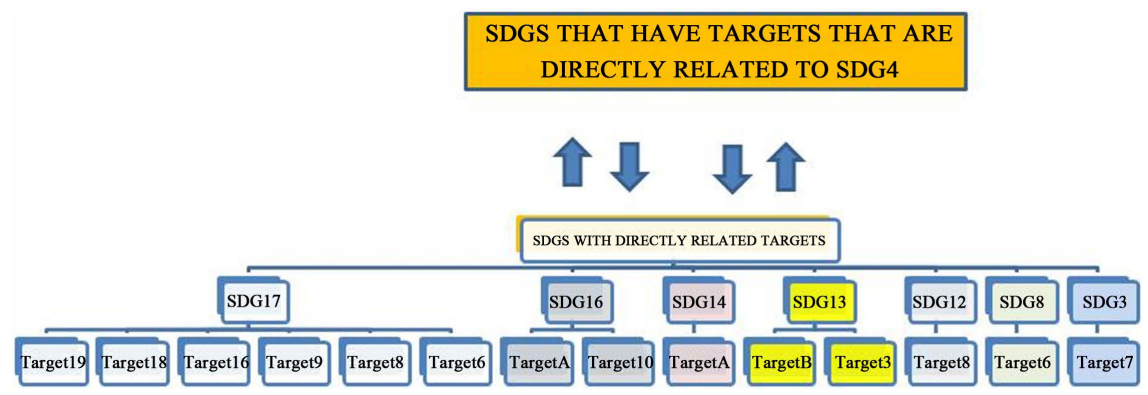

Figure 3. Source: Conceptualized by the researchers.

Figure 3 showing in a hierarchical format SDGs with several targets that are directly aligned with SDG 4 from the assessment of Goal to Goal/Target analysis (SD Goal 4 to the other SD goals and targets).

\subsection{Assessing SDG 4 Targets to the Targets of the Other 16 SDGS}

Table 4 is the summary of Tables $5-11$. Tables $5-11$ detailed the targets of SDG 4 that have either direct or indirect relationships with the other 16 SDGs. At this level, it can be seen that although the targets of SDG 1 has no direct relationship with SDG 4, it has the most (50) indirectly interrelated targets with SDG 3 which has 46 indirectly related and 8 directly related targets. Equally, while we could not establish any indirect relationship between SDG 4 and SDG 15, both goals had as many as 9 indirectly interrelated targets and SDG 7 with SDG 4 showed the least interrelatedness.

Table 4. Below showing summary findings of the assessments of direct and indirect relationships between SDG 4 targets with the targets of the other 16 SDGs.

\begin{tabular}{cccccccccccccccccccc}
\hline & \multicolumn{11}{c}{ Direct and indirectly relationships between SDG 4 with the other 16 SDGS } \\
\hline SDG & 1 & 2 & 3 & 5 & 6 & 7 & 8 & 9 & 10 & 11 & 12 & 13 & 14 & 15 & 16 & 17 & TOTAL \\
\hline Directly related & 0 & 0 & 8 & 0 & 0 & 0 & 10 & 0 & 0 & 0 & 4 & 9 & 2 & 0 & 2 & 3 & 38 \\
Indirectly related & 50 & 14 & 46 & 15 & 16 & 2 & 40 & 9 & 20 & 16 & 15 & 6 & 6 & 9 & 25 & 33 & 322 \\
$\quad$ Total & 50 & 14 & 54 & 15 & 16 & 2 & 50 & 9 & 20 & 16 & 19 & 15 & 8 & 9 & 27 & 36 & 360 \\
\hline
\end{tabular}

Table 5. Below showing findings of the assessments of direct and indirect relationships between SDG 4 targets with the targets of 3 SDGs (SDGs 1, 2 and 3).

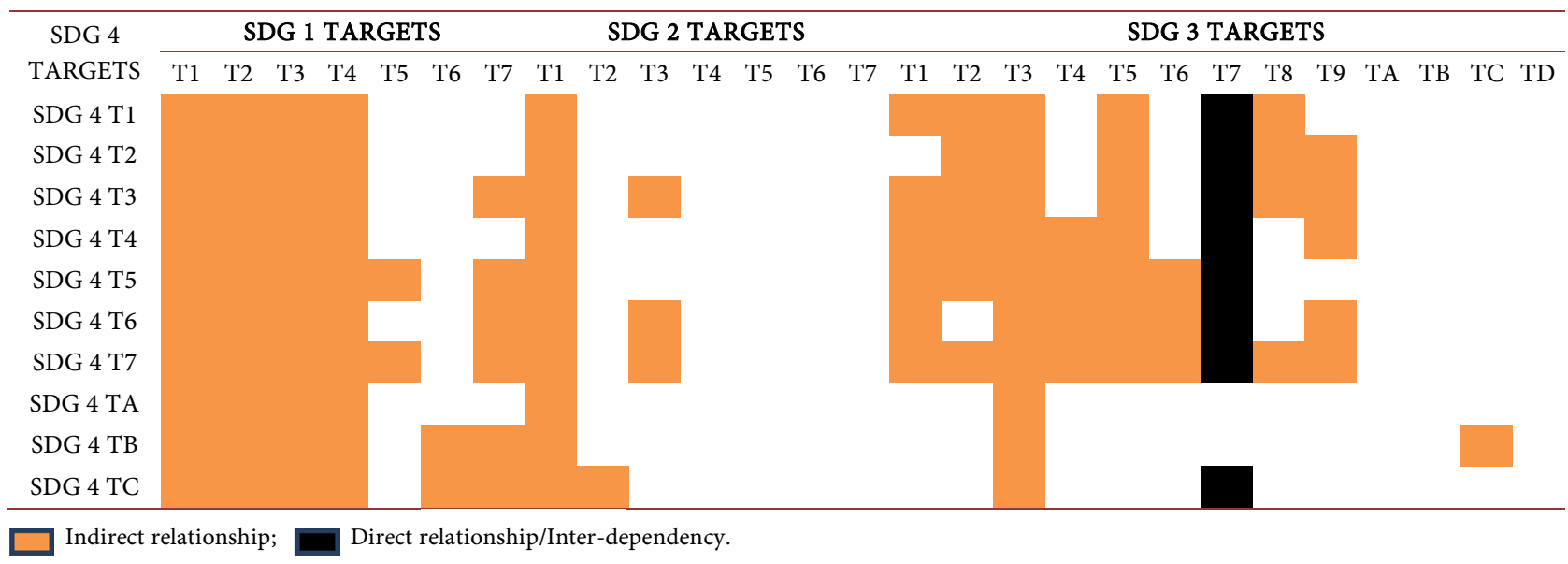


Table 6. Below showing findings of the assessments of direct and indirect relationships between SDG 4 targets with the targets of 3 SDGs (SDGs 5, 6 and 7).

\begin{tabular}{|c|c|c|c|c|c|c|c|c|c|c|c|c|c|c|c|c|c|c|c|c|c|c|}
\hline \multirow{2}{*}{$\begin{array}{c}\text { SDG } 4 \\
\text { TARGETS }\end{array}$} & \multicolumn{9}{|c|}{ SDG 5 TARGETS } & \multicolumn{8}{|c|}{ SDG 6 TARGETS } & \multicolumn{5}{|c|}{ SDG 7 TARGETS } \\
\hline & $\mathrm{T} 1$ & $\mathrm{~T} 2$ & T3 & $\mathrm{T} 4$ & T5 & T6 & TA & $\mathrm{TB}$ & $\mathrm{TC}$ & $\mathrm{T} 1$ & $\mathrm{~T} 2$ & T3 & $\mathrm{T} 4$ & T5 & T6 & TA & $\mathrm{TB}$ & $\mathrm{T} 1$ & $\mathrm{~T} 2$ & $\mathrm{~T} 3$ & TA & $\mathrm{TB}$ \\
\hline SDG 4 T1 & & & & & & & & & & & & & & & & & & & & & & \\
\hline SDG 4 T2 & & & & & & & & & & & & & & & & & & & & & & \\
\hline SDG 4 T3 & & & & & & & & & & & & & & & & & & & & & & \\
\hline SDG 4 T4 & & & & & & & & & & & & & & & & & & & & & & \\
\hline SDG 4 T5 & & & & & & & & & & & & & & & & & & & & & & \\
\hline SDG 4 T6 & & & & & & & & & & & & & & & & & & & & & & \\
\hline SDG 4 T7 & & & & & & & & & & & & & & & & & & & & & & \\
\hline SDG 4 TA & & & & & & & & & & & & & & & & & & & & & & \\
\hline SDG 4 TB & & & & & & & & & & & & & & & & & & & & & & \\
\hline SDG 4 TC & & & & & & & & & & & & & & & & & & & & & & \\
\hline
\end{tabular}

Table 7. Below showing findings of the assessments of direct and indirect relationships between SDG 4 targets with the targets of 3 SDGs (SDGs 8, 9 and 10).

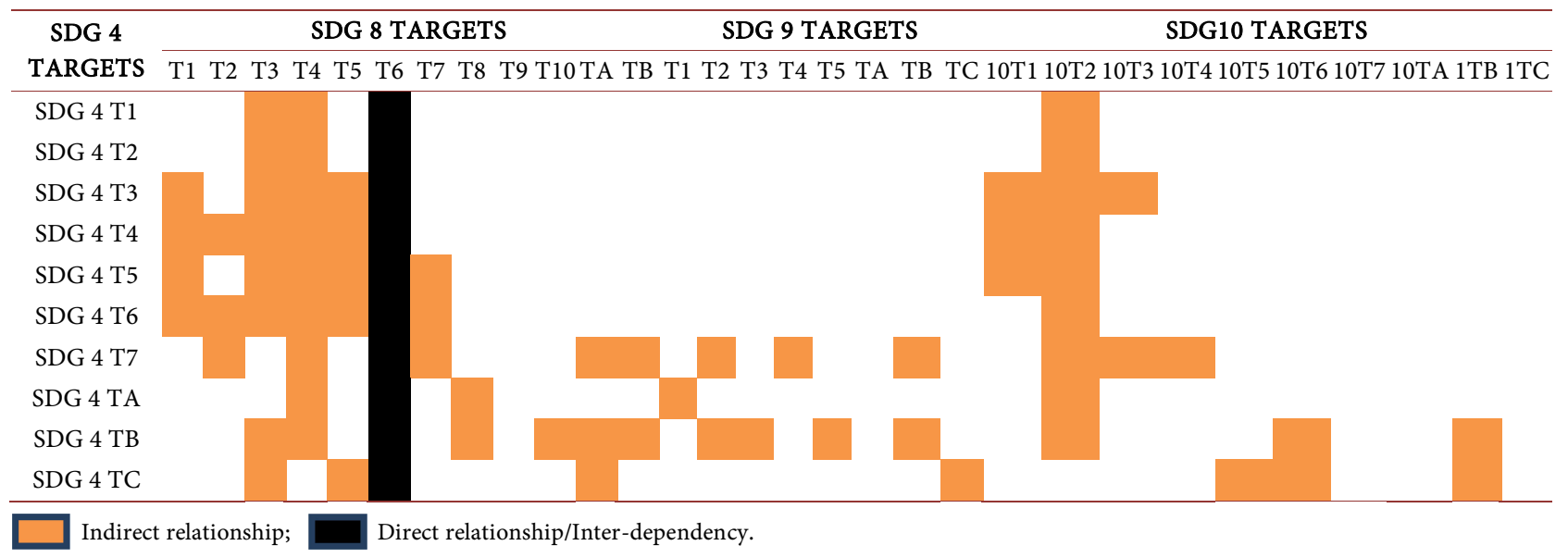

Table 8. Below showing findings of the assessments of direct and indirect relationships between SDG 4 targets with the targets of 3 SDGs (SDGs 11, 12 and 13).

\begin{tabular}{|c|c|c|c|c|c|c|c|c|c|c|c|c|c|c|c|c|c|c|c|c|c|c|c|c|c|c|}
\hline \multirow{3}{*}{ SDG 4} & \multicolumn{10}{|c|}{ SDG 11} & \multicolumn{11}{|c|}{ SDG 12} & \multicolumn{5}{|c|}{ SDG 13} \\
\hline & 11 & 11 & 11 & 11 & 11 & 11 & 11 & 11 & 11 & 11 & 12 & 12 & 12 & 12 & 12 & 12 & 12 & 12 & 12 & 12 & 12 & 13 & 13 & 13 & 13 & 13 \\
\hline & $\mathrm{T} 1$ & $\mathrm{~T} 2$ & $\mathrm{~T} 3$ & $\mathrm{~T} 4$ & T5 & T6 & T7 & TA & TB & TC & $\mathrm{T} 1$ & $\mathrm{~T} 2$ & T3 & $\mathrm{T} 4$ & T5 & T6 & $\mathrm{T} 7$ & $\mathrm{~T} 8$ & TA & TB & $\mathrm{TC}$ & $\mathrm{T} 1$ & $\mathrm{~T} 2$ & T3 & TA & TB \\
\hline SDG 4 T1 & & & & & & & & & & & & & & & & & & & & & & & & & & \\
\hline SDG 4 T2 & & & & & & & & & & & & & & & & & & & & & & & & & & \\
\hline SDG 4 T3 & & & & & & & & & & & & & & & & & & & & & & & & & & \\
\hline SDG $4 \mathrm{~T} 4$ & & & & & & & & & & & & & & & & & & & & & & & & & & \\
\hline SDG 4 T5 & & & & & & & & & & & & & & & & & & & & & & & & & & \\
\hline SDG 4 T6 & & & & & & & & & & & & & & & & & & & & & & & & & & \\
\hline SDG 4 T7 & & & & & & & & & & & & & & & & & & & & & & & & & & \\
\hline SDG 4 TA & & & & & & & & & & & & & & & & & & & & & & & & & & \\
\hline SDG 4 TB & & & & & & & & & & & & & & & & & & & & & & & & & & \\
\hline SDG $4 \mathrm{TC}$ & & & & & & & & & & & & & & & & & & & & & & & & & & \\
\hline
\end{tabular}


Table 9. Below showing findings of the assessments of direct and indirect relationships between SDG 4 targets with the targets of SDG 14 and 15 .

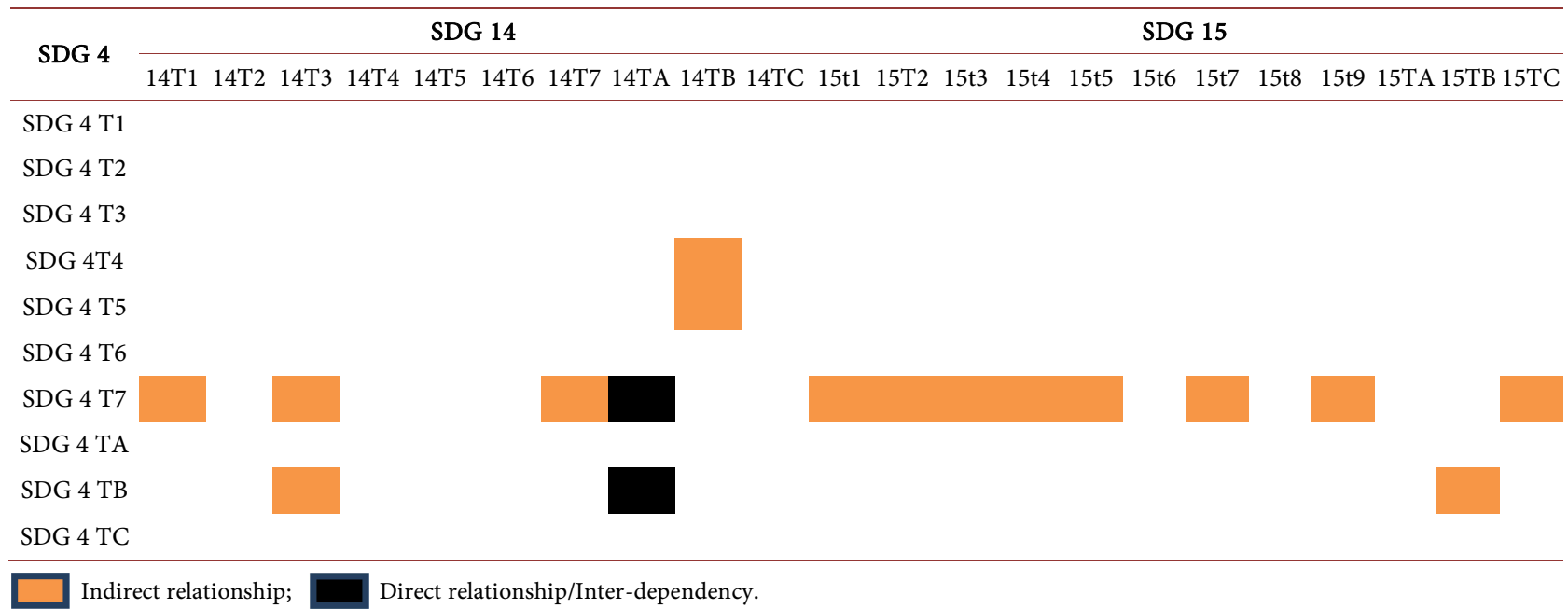

Table 10. Below showing findings of the assessments of direct and indirect relationships between SDG 4 targets with the targets of SDG 16.

\begin{tabular}{|c|c|c|c|c|c|c|c|c|c|c|c|c|}
\hline \multirow{2}{*}{ SDG 4} & \multicolumn{12}{|c|}{ SDG 16} \\
\hline & $16 \mathrm{~T} 1$ & $16 \mathrm{~T} 2$ & $16 \mathrm{~T} 3$ & $16 \mathrm{~T} 4$ & $16 \mathrm{~T} 5$ & $16 \mathrm{~T} 6$ & $16 \mathrm{~T} 7$ & $16 \mathrm{~T} 8$ & $16 \mathrm{~T} 9$ & 16T10 & 16TA & $16 \mathrm{~TB}$ \\
\hline SDG 4 T1 & & & & & & & & & & & & \\
\hline $\mathrm{SDG} 4 \mathrm{~T} 2$ & & & & & & & & & & & & \\
\hline SDG 4 T3 & & & & & & & & & & & & \\
\hline SDG 4T4 & & & & & & & & & & & & \\
\hline SDG 4 T5 & & & & & & & & & & & & \\
\hline SDG 4 T6 & & & & & & & & & & & & \\
\hline SDG 4 T7 & & & & & & & & & & & & \\
\hline SDG 4 TA & & & & & & & & & & & & \\
\hline SDG 4 TB & & & & & & & & & & & & \\
\hline SDG 4 TC & & & & & & & & & & & & \\
\hline
\end{tabular}

Table 11. Below showing findings of the assessments of direct and indirect relationships between SDG 4 targets with the targets of SDG 17.

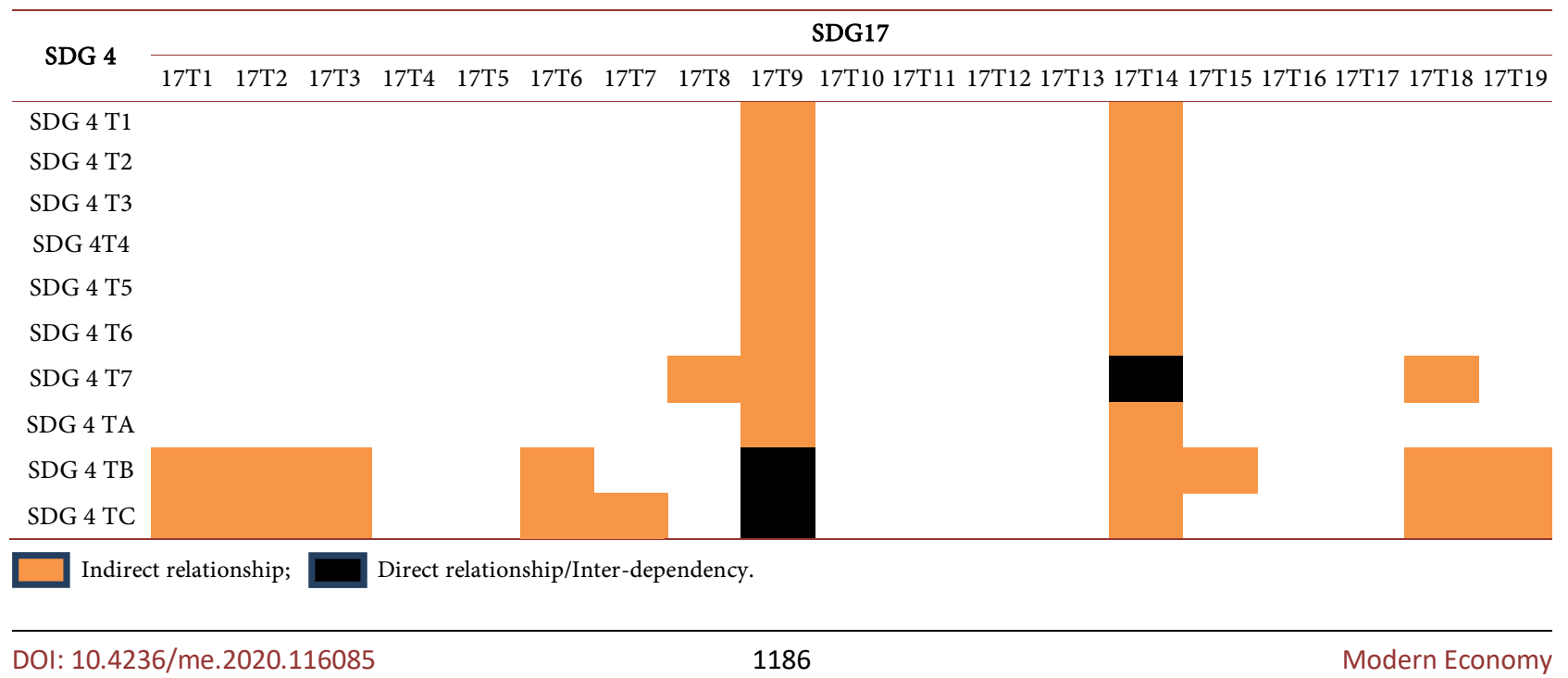




\section{Findings}

SDG 1-No Poverty: all 64 relationships were found to be indirect. The first of these is target 1.1 which talks about eradicating extreme poverty by ensuring that people everywhere live on more than $\$ 1.25$ a day.

We know that education increases employability and also impacts productivity. We also know years of education are positively correlated with income. Education and life-long learning are therefore related to this target via an enabling route. Equally, target 1.4 which reads "ensure that all men and women, particularly the poor and the vulnerable, have equal rights to economic resources, as well as access to basic services, ownership, and control over land and other forms of property, inheritance, natural resources, appropriate new technology, and financial services including microfinance" is also indirectly related to SDG 4 as it deals with developing human capacities, competencies and skills for productive work all of which have education as their raison d'etre. Finally, target $1 \mathrm{~b}$ involves education since all evidence shows that education is one of the strongest and most effective pro-poor and gender-sensitive development strategies.

SDG 2 reads thus-"End hunger, achieve food security and improved nutrition and promote sustainable agriculture". As in the case of SDG 1, education and knowledge acquisition are critical to achieving this goal. First of all, most sustainable agricultural practices are acquired through some form of learning usually made possible through extension services and on the job training for farmers. When one looks closely at the targets for SDG 2, one can pick out two targets that involve education and capacity building though it must be said that the relationship of each of these to SDG 4 is indirect. Target 2.3 "Double the agricultural productivity and the incomes of small-scale food producers, particularly women, indigenous peoples, family farmers, pastoralists and fishers, including through secure and equal access to land, other productive resources and inputs, knowledge, financial services, markets, and opportunities for value addition and non-farm employment" mention of knowledge as one of the means for doubling agricultural productivity and farmers' incomes is a recognition of the role of education in achieving this target. A similar enabling but indirect relationship exists between target 2.a and SDG 4. This target reads "Increase investment, including through enhanced international cooperation, in rural infrastructure, agricultural research and extension services, technology development, and plant and livestock gene banks to enhance agricultural productive capacity in developing countries, in particular in the least developed countries".

SDG 3 reads "Ensure healthy lives and promote well-being for at all ages" Education is important for the promotion of good health, for good sanitation, the pursuit of sexual and reproductive health, child and maternal health, drug abuse and accident prevention through behaviour change and for the pursuit of community health. For all of these, educating people from infancy to all stages of life through community and mass education interventions, health sensitizations and campaigns are critical in achieving the SDG 3. Specifically, target 3.7- 
"Ensure universal access to sexual and reproductive health care services, including for family planning, information and education, and the integration of reproductive health into national strategies and programmes" has a direct relationship with SDG 4.

SDG 5-Gender Equality: the traditions and cultures of most of the Nigerian societies give superior status to a male child and it is difficult to suddenly change entrenched traditional/cultural practices. In many communities and homes, it is a taboo for a woman to take a commanding position when a father figure is still in existence; this is so even when the woman is the breadwinner. Many cultural and religious practices relegate women to the background. Education is a critical tool to change these tendencies. Continual educational exposures and activities are gradually changing these tendencies. In many communities, the situation is in reverse mode as more women acquire educational qualifications even at higher levels than their male counterparts and over time the earning power of women may supersede that of the male folks. Two of the targets here have indirect relationships with SDG 4. These are 5.b "Enhance the use of enabling technologies, in particular ICT, to promote women's empowerment", a target that has-indirect relationship with SDG 4. It is also worth noting that this target also has implications for the use of new technologies in the pursuit of gender equality. Target 5.6 also has an indirect relationship with SDG 4. It reads"Ensure universal access to sexual and reproductive health and reproductive rights as agreed by the Programme of Action of the ICPD and the Beijing Platform for Action and the outcome documents of their review conferences".

SDG 6 deals with clean water and Sanitation. The central challenges of water and sanitation are essentially challenges that can be addressed using a blend of awareness creation, information, and communication for behaviour change, all of which have the education and life-long learning at their core. It is interventions of the nature mentioned earlier that will enable people to understand the dangers of open defecation and the use of contaminated water. Education will also improve the efficiency of the effective utilization of limited water sources and enable people to have access to adequate sanitation and hygienic lifestyles so vital for healthy living and disease prevention. Target $6 \mathrm{a}$ implies educational action at the level of participating nations-the giveaway being the expression "Expand international cooperation and capacity-building support to developing countries in water and sanitation" Capacity building implies a significant portion of learning and training which again relates to the intentions of SDG 4. Equally, Target 6.b which reads Support and strengthen the participation of local communities for improving water and sanitation management has an indirect relationship with SDG 4. The same is true for target 6.2-"Achieve access to adequate and equitable sanitation and hygiene for all, and end open defecation, paying special attention to the needs of women and girls and those in vulnerable situations" as well as target 6.6 "Protect and restore water-related ecosystems, including mountains, forests, wetlands, rivers, aquifers and lakes". All the relationships between SDG 4 and these three targets are indirect. For 
example, sustainable water-related ecosystem protection usually involves community participation and the community members are usually conscientious and empowered through knowledge and training on how to protect and manage such an ecosystem.

SDG 7 focuses on sustainable energy and deals with affordable and clean energy. Most cases of inefficiencies in energy use arise from ignorance and or poor knowledge base. Efforts to improve energy efficiency are usually pursued at two levels-at the level of the design of new technologies and at the level of inculcating positive behaviour change which again is education. Again, the link to SDG 4 is indirect.

SDG 8 deals with Decent Work and Economic Growth. Education is the tool to open up the creativity of the people, to provide skills that will make people become employable and also become employers of labour, governments can also benefit in the best ways to utilise the revenue available to them, to support industries and other skill acquisition centres, to advice people against unsustainable activities and livelihoods that degrade the environment, to educate people against forced or child labour, to encourage the right use of organised labour, to encourage more in-house value addition of products before they are exported and in so doing provide additional employment for the people. Two targets here

8.a-“Reduce the proportion of youth not in employment through education and training" and

8.b-(Indirect) "Develop and operationalize a global strategy for youth employment and implement the ILO Global Jobs Pact" have relationships with SDG 4 , target 8.6 having a direct link whilst $8 \mathrm{~b}$ has an indirect relationship with it.

SDG 9 on Innovation and infrastructure has major implications for SDG 4 and education. Education builds talents and skills. It also unleashes hidden potentials and creativity, and thus drives innovation. Sustainable human development relies on the ability of the human mind to innovate and Education greatly enhances the human ability to innovate and build new infrastructure and technologies.

SDG 10 addresses the question of-Reducing Inequalities. Education has often been described as a great equaliser. It is said for Education that it can arrest the inter-generational transmission of poverty. When properly applied, education can help the poor understand their situation and how to take the right measures out of poverty. One of the targets of this SDG, target 10.2-"Empower and promote the social, economic and political inclusion of all irrespective of age, sex, disability, race, ethnicity, origin, religion, economic or other status" relates to the aspirations of SDG 4.

When it comes to SDG 11 which focuses on Sustainable Cities and Communities, it is important to remind ourselves that education is critical for building people's social, cultural and civics skills, which are indispensable skills for functioning in our new sustainable cities and communities.

SDG 12 deals with responsible consumption and production. The truth of our 
world is that natural resources like forests are depleting because of non-sustainable consumption patterns. Many resources like oceans are also losing their values and their inhabitants are becoming endangered, mineral resources are depleting and without efficient utilization, these will be depleted faster than expected. Education will enable people to take responsible actions to reverse these trends. People must be educated to adopt responsible lifestyles, consumption, and production patterns without which, excessive pollution and consumption will push most natural resources into levels beyond their carrying capacities and the realm of extinction or exhaustion. Target 8 of this SDG specifically espouses the importance of education thus: "By 2030, ensure that people everywhere have the relevant information and awareness for sustainable development and lifestyles in harmony with nature" and the relationship to SDG 4 is direct.

SDG 13 CLIMATE ACTION looks at the effects of global warming and other actions, including the increasing devastation of the environment from consequences of climate change and this has been one of the areas that continuous education through the mass media and social media has highlighted most. Despite the information available, people are still reluctant to change their current modes of operations for economic reasons. The poor people are still aggressively harvesting the forest as a source of income and sustenance due to poverty pressures. Nations are still ramping up their utilization of fossil fuels. That is why more education is required. That is why every child in the world needs to be educated to understand the harm these practices are causing to our continued existence on earth. Given the importance of education to achieve this goal, two targets were set by UN that is related to education: SDG 13.3 "Improve education, awareness-raising and human and institutional capacity on climate change mitigation, adaptation, impact reduction and early warning" and 13.b "Promote mechanisms for raising capacity for effective climate change-related planning and management in Least Developed Coutiries, including focusing on women, youth, local and marginalized communities. Target 13.3 has a direct relationship whilst 13.b has an indirect relationship with SDG 4".

SDG 14 has Life Below Water: There is massive pollution of the oceans from harmful chemicals, pesticides, fertilizers, etc. and solid wastes of which plastics are the chief offenders. There are unregulated harvesting and overfishing of the resources in the oceans and seas that are unsustainable. We must develop stringent regulations that we must strictly enforce after people have been educated on the consequences. The ocean is the buffer together with forests without which life on earth will be terrible. Building the capacities and providing some form of education for people to grow fishes etc. as an alternate source of food will be an effective complementary strategy to reduce over-harvesting and overfishing.

Target 14a of this SDG-"Increase scientific knowledge, develop research capacities and transfer marine technology taking into account the Intergovernmental Oceanographic Commission Criteria and Guidelines on the Transfer of Marine, Technology, to improve ocean health and to enhance the contribu- 
tion of marine biodiversity to the development of developing countries, in particular, SIDS and LDCs" has an indirect relationship with SDG 4.

SDG 15 deals with Life on Land. It is common knowledge that life on land, including man, must be protected for sustainable development to be achieved. Achieving this goal demands sustainable use of terrestrial and inland water resources, the effective management of the remaining forests on earth, the maintaining of bio-diversities and reducing desert encroachments, and preventing degradation of natural habitats. These can be achieved through several options including laws, legislations, rewards, incentives, etc. But beyond these, formal and informal educational interventions to enlighten the people of the world and also to ensure that future generations are well informed of the consequences of wrong management of these resources bequeathed to us by providence are of critical importance.

SDG 16-Peace, Justice and Strong Institutions: Education is critical in the efforts to achieve this goal. Without Justice, there will be no sustainable peace, and strong institutions are critical in ensuring the rule of laws is enforced and impunity is checked. Peaceful coexistence and conflict management/sensitization talks in communities are required due to increasing youth restiveness, continuous militancy and situations of endemic conflicts, especially in developing countries. Religious extremism and bigotry are becoming part of our socio-political landscape. Two targets in this SDG are related to education and they do so directly. These are 16.10 which reads "Ensure public access to information and protect fundamental freedoms, in accordance with national legislation and international agreements" and Target $16 \mathrm{a}$ which reads "Strengthen relevant national institutions, including through international cooperation, for building capacity at all levels, in particular in developing countries, to prevent violence and combat terrorism and crime".

SDG 17-Partnership for the Goal: Developing nations will not be able to benefit from effective partnerships if they are not well educated or their capacities built to maximally benefit from the opportunities this goal provides. Developing nations must understand the best ways to utilize these supports to enhance their development. May we seek permission to extensively quote from SDG 17 to illustrate the centrality of Education in the pursuit and attainment of this goal, six of whose targets are related to education.

Target 17.6 "Enhance North-South, South-South and triangular regional and international cooperation on and access to science, technology and innovation and enhance knowledge sharing on mutually agreed terms, including through improved coordination among existing mechanisms, in particular at the United Nations level, and through a global technology facilitation mechanism".

Target 17.8 "Fully operationalize the technology bank and science, technology and innovation capacity-building mechanism for least developed countries by 2017 and enhance the use of enabling technology, in particular information and communications technology". 
Target 17.9 "Enhance international support for implementing effective and targeted capacity-building in developing countries to support national plans to implement all the sustainable development goals, including through North-South, South-South and triangular cooperation".

Target 17.16 "Enhance the global partnership for sustainable development, complemented by multi-stakeholder partnerships that mobilize and share knowledge, expertise, technology and financial resources, to support the achievement of the sustainable development goals in all countries, in particular developing countries",

Target 17.18 "By 2020, enhance capacity-building support to developing countries, including for least developed countries and small island developing States, to increase significantly the availability of high-quality, timely and reliable data disaggregated by income, gender, age, race, ethnicity, migratory status, disability, geographic location and other characteristics relevant in national contexts". The links to education are also indirect. Finally, target 17.19 reads "By 2030, build on existing initiatives to develop measurements of progress on sustainable development that complement gross domestic product, and support statistical capacity-building in developing countries".

\section{Discussion}

Assessing the inter-dependencies (direct relationships) and inter-relatedness (indirect relationships) between SDG 4 as a goal and the targets of SDG 4 on one hand with the other SDGs resulted in some discrepancy of identified links. The reason being that while SDG 4 as a goal will relate with each of the other SDGs as a unit, doing the same thing at the SDG 4 target levels, means assessing each of the other SDG targets from the perspective of the 10 different SDG 4 targets.

As a result of the above, while at the SDG 4 goal level we can identify 14 direct relationships, at the SDG 4 target levels we noted 38 direct relationships.

There are 10 SDG 4 targets and a total of 159 targets for the remaining 16 SDGs. That means there is a possibility of 1590 linkage combinations. However, we identified 360 actual linkages between SDG 4 and the rest 16 SDGs, which is $22.6 \%$ of all the possible target combinations. Out of the 360 linkages only 38 linkages were identified to have direct relationships (inter-dependent). This is about $10.6 \%$ of all the identified linkages in this study. The remaining 322 linkages were adjudged as indirect (inter-related).

SDG 4 is highly related to SDGs 1, 3, 8 and 17 with each having between 36 and 54 identified target similarities. This is followed by the rest of the SDGs 2, 5 , $6,9,11,12,13,14,15$ and 16. The links between SDG 4 and SDG 7 are just 2 and it is therefore the pair with the least interrelationship in this study.

The above findings go to buttress the position that the Sustainable Development Goals are directly-related/interdependent or indirectly-related/inter-related in many respects. 


\section{Conclusion}

The Sustainable Development Goals are inter-dependent or inter-related in many respects. There are 360 interlinks between SDG 4 and the other 16 SDGs. Out of which 38 are directly related (inter-dependent) while 322 indirect links (inter-relatedness) were equally observed. SDG 4 is highly related to SDGs $1,3,8$ and 17. This is followed by SDGs 2, 5, 6, 9, 11, 12, 13, 14, 15 and 16. The links between SDG 4 and SDG 7 are just 2, and it can be deduced that they are the least related pair.

This means that while you are trying to resolve a challenge, you are inadvertently helping in resolving other issues. Studies like this together with studying interventions that have multiplier effects like home grown school feeding programme and the adoption of online teaching/learning and more online conferencing, meetings etc. as a result of the Corona Virus (COVID-19) impact will be helpful ways to apply this type of thinking. It becomes an area for further studies in the future.

Many organizations are adopting video conferencing meeting to the expensive physical meeting where a hall is required, feeding or snacks and transportation logistics will be arranged as a means of preventing the spread of the virus but inadvertently introducing cheaper means of working requiring less transportation, less use of fossil fuel and less exposure to accidents.

It is important to harmonize and benefit from the synergy of pursuing several SDGs at the same time. It is also true that meaningful progress cannot be achieved, if support from developed nations, (in line with SDG 17-Partnership to achieve the Goal) is not given the priority it deserves by the developed nations and their associated development bodies including the UN agencies like the UNESCO, Global Regional Centre of Expertise (RCE) Service Centre, United Nations University Systems and others. Developed nations should endeavour to give more scholarship awards to deserving candidates from developing nations and properly communicate how much of such scholarships they have awarded annually so that UN and its associated agencies can collate the performance nation by nation, developed nations should collaborate with and also build the capacities of developing nations in bringing up appropriate technologies relevant to the developmental levels and needs of the beneficiary nations/communities to help them achieve the aspirations of SDG 4 and others.

For developing nations and even developed ones to get the greatest benefits from the implementation of the SDGs, we must all plan effectively giving priority to interventions that have the potentials to achieve multi-goal needs and with inherent positive multiplier effects.

\section{Acknowledgements}

We thank Mr. Dango Wakwe Lawrence (Manager, CIRCI) and Mr. Owanari Chukwuma Lawrence for the editorial support given. 


\section{Conflicts of Interest}

The authors declare no conflicts of interest regarding the publication of this paper.

\section{References}

Freeman, R., \& Yearworth, M. (2014). Review of Literature on Systems Thinking and System Dynamics for Policy Making Technical Report.

Griggs, D., Stafford Smith, M., Rockström, J., Öhman, M. C., Gaffney, O., Glaser, G., Kanie, N., Noble, I., Steffen, W., \& Shyamsundar, P. (2014). An Integrated Framework for Sustainable Development Goals. Ecology and Society, 19, 49.

https://doi.org/10.5751/ES-07082-190449

ICSU (2017). A Guide to SDG Interactions: From Science to Implementation. Paris: International Council for Science.

Ihebuzor, N. A. (2014) An Incentive Scheme to Increase Female Access to and Completion of Basic Education in the Democratic Republic of the Congo. Open Access Library Journal, 1, e1023. https://doi.org/10.4236/oalib.1101023

INCOSE UK (2010). What Is Systems Thinking? U. K. C. International Council on Systems Engineering.

Lawrence, A. W. (2018). Some Governance and Peaceful Coexistence Issues for Sustainable Advancement: A Nigerian Perspective (2nd ed.). T\&D Press Ltd.

https://www.amazon.co.uk/Governance-Peaceful-Coexistence-Sustainable-Advanceme nt-ebook/dp/B079HJBWX8/ref=sr_1_1?s=books\&ie=UTF8\&qid=1527510031\&sr=1-1 \&keywords=some+governance + and + peaceful+coexistence + issues 7

Lawrence, A. W., \& Lawrence, D. O. (2019). Macro-Level Considerations for Effective Implementation of Sustainable Development Interventions. International Journal of Development and Economic Sustainability, 7, No. 6.

Nilsson, M., Griggs, D., \& Visbeck, M. (2016). Map the Interactions of Sustainable Development Goals. Nature, 534, 320-322. https://doi.org/10.1038/534320a

Reynolds, M., Blackmore, C., Ison, R., Shah, R., \& Wedlock, E. (2018). The Role of Systems Thinking in the Practice of Implementing Sustainable Development Goals. In L. Filho (Ed.), Handbook of Sustainability Science and Research. World Sustainability Series, Springer International Publishing AG W. https://doi.org/10.1007/978-3-319-63007-6_42

Senge, P. M. (1990). The Fifth Discipline. New York: Doubleday.

United Nations (2015a). \#Envision2030: 17 Goals to Transform the World for Persons with Disabilities. https://www.un.org/development/desa/disabilities/envision2030.html

United Nations (2015b). Transforming Our World: The 2030 Agenda for Sustainable Development. https://sustainabledevelopment.un.org/post2015/transformingourworld

Zhou, X., Moinuddin, M., \& Xu, M. (2017). Sustainable Development Goals Interlinkages and Network Analysis: A Practical Tool for SDG Integration and Policy CoherenceInstitute for Global Environmental Strategies.

https://www.iges.or.jp/en/pub/sustainable-development-goals-interlinkages/en 